\title{
Implementation of AVCS using Kalman Filter and PID Controller in Autonomous Self Guided Vehicle
}

\author{
D. Sivaraj \\ Asst. Prof. ECE Dept. \\ PSG College of Technology, \\ Coimbatore, India.
}

\author{
A. Kandaswamy \\ HoD, BME, Dept., \\ PSG College of Technology, \\ Coimbatore, India.
}

\author{
V. Rajasekar, \\ P.B.Sankarganesh, \\ G. Manikandan \\ PSG College of Technology \\ Coimbatore, India.
}

\begin{abstract}
Advanced Vehicle Control Systems (AVCS) is a key technology for Intelligent Transportation System (ITS) and Intelligent Vehicle Control System (IVCS). AVCS involves automatic steering, acceleration and braking control of fully autonomous vehicles. The unmanned control of the steering wheel is one of the most important challenges faced by the researchers. This paper proposes control architecture for automatic steering, acceleration and braking control of a self guided vehicle. Self guided vehicle is a line follower which tracks a black line on a white surface, through an array of infrared sensors. In line following, the readings that show deviation from the line are considered as lateral error and the proposed algorithm works towards minimizing the lateral error. Calculation of the lateral error and filtering the error values using Kalman filter is the first level of error calculation. Kalman filter protects the steering action from erroneous sensor values. PID control algorithm uses the filtered value and calculates the required steer to achieve the zero lateral error. The proposed adaptive speed control algorithm uses the speed boosting techniques for the longitudinal control of the vehicle. The experimental results show that the combination of Kalman filter with PID for lateral control reduces trajectory error to a minimum level and adaptive speed control algorithm for longitudinal control provides smooth accelerations over the entire track. Thus proposed algorithm gives better performance in both the lateral and longitudinal control.
\end{abstract}

\section{Keywords}

Kalman filter, PID control, lateral and longitudinal control, advanced vehicle control system.

\section{INTRODUCTION}

Intelligent Transportation Systems (ITS) are those utilizing synergetic technologies and systems engineering concepts to develop and improve transportation systems of all kinds. To this end, new technologies and computers have been applied to freeway, traffic and transit systems [1] [2]. ITS applies the cutting edge technology to achieve efficient, reliable, safer and more comfortable highways, inland waterways, airports, ports and linkages among all these means of transport [3].

The projected ITS infrastructure benefits over the duration from 1996 to 2015 are savings in cost due to accidents up to $44 \%$, time savings of $41 \%$, emissions/fuel can be reduced by $6 \%$, operating cost savings of $5 \%$, cost savings to agencies contributing a factor of $4 \%$ and others providing less than $1 \%$ [4]. Congestion costs in the United States are estimated to be $\$ 100$ billion annually, traffic accidents caused by congestion drains away another $\$ 70$ billion per year. At the same time, new pavement construction is no longer in itself a complete solution to address the transportation needs [5].

In technology perspective six major categories of ITS are reviewed [6], Advanced Traffic Management Systems (ATMS), Advanced Traveler Information Systems (ATIS), Advanced Public Transportation Systems (APTS), Fleet Management and Control Systems (FMCS), Advanced Rural Transportation systems (ARTS) and Advanced Vehicle Control Systems (AVCS). The components of AVCS in ITS hierarchy [5][7] are shown in the figure 1. AVCS integrates sensors, computers and control systems to assist and alert drivers or to take a part of vehicle driving. The main purposes of these systems are to increase safety, to decrease congestions on roads and highways, and to improve road systems productivity [8]. AVCS also includes advanced cruise control, automated steering control for lane keeping and autonomous behavior, including automated stopping and lane changes in reaction to other vehicles [5].

AVCS involves several safety critical functions such as vehicle longitudinal and lateral control. Because of the safety critical nature, it is required that the system will be able to prevent or mitigate hazardous conditions that would be otherwise dealt by human operators [9]. To facilitate this various technologies from the fields like sensors, communication, computation, electromechanical actuators, software and special tool facilities are needed [10].

There are two ways to design steering controllers: imitating human drivers and using dynamic models of the car and control methods based on linear theory. Controllers for lateral and longitudinal control have been developed based on classical geometric control Global Positioning System (GPS) and intervehicle communications [11], using fuzzy logic techniques to address both challenges and incorporate human procedural knowledge into the vehicle control algorithms [12]. Image processing techniques are used to guide the autonomous vehicles from losing the track when the guide line is missing [13] and to identify obstacles and to traverse them accordingly. Artificial vision systems and the neural network based rapidly adapting lateral position handler (RALPH) were used in Navlab vehicle series [14]. 


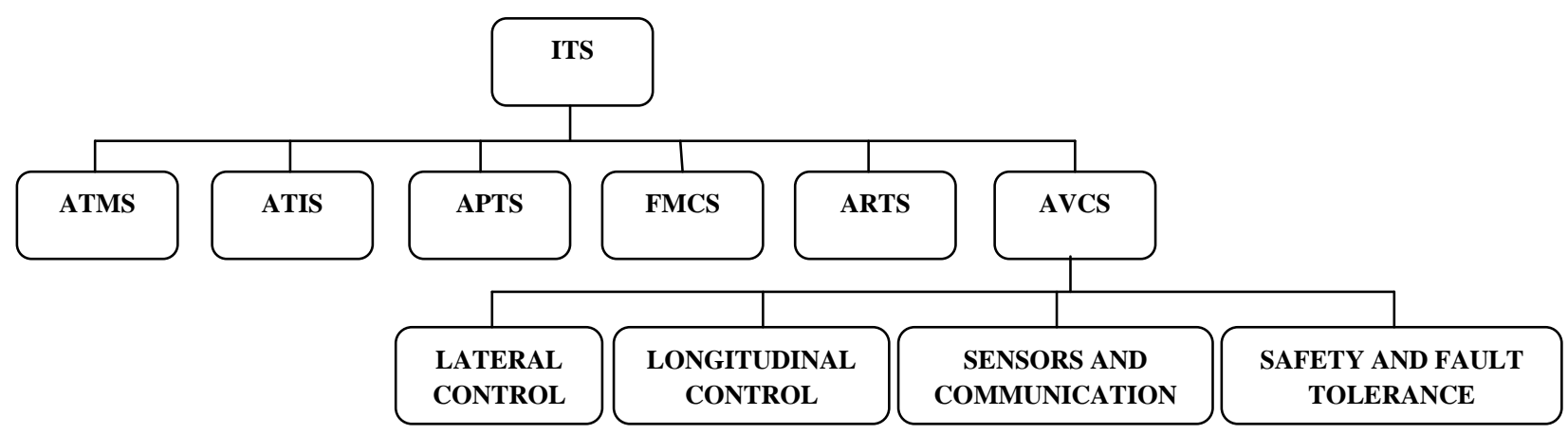

Figure 1: AVCS in ITS Hierarchy

A vehicle is a typical system where driving models, sensory information, objectives, constraints and control actions are essentially inaccurate. In the proposed approach, Kalman Filter is used to eliminate or minimize these inaccuracies, thus facilitating to control the system more effectively than other classical approaches. Automatic steering control architecture based on the combination of Kalman filter and PID control in cascade for managing the lateral control of self guided autonomous vehicle is being proposed.

This paper is organized as follows: Section 2 presents the vehicle instrumentation of the autonomous self guided vehicle covering the hardware organization. Section 3 describes about the lateral control algorithm and its organization. Section 4 elucidate about the longitudinal control organization which covers the adaptive speed control of the vehicle Section 5 addresses the experimentation and the results obtained.

\section{VEHICLE INSTRUMENTATION}

The autonomous self guided vehicle and its block diagram structure shown in figure 3 and figure 2. It consists of controller board driven by the battery and interfaced with IR sensor array. Servo motor with front axle for front wheel steer mechanism and DC motor with rear axle and encoder for rear wheel drive mechanism. The vehicle is controlled by Freescale S12X microcontroller.

The sensor board consists of four SFH4550 Infrared LEDs, which provide high radiant intensity, narrow emission and short switching time and seven SFH314 NPN phototransistors having good radiant sensitive area. The IR LEDs emits IR rays that gets reflected from the track, modifies the voltage across photo transistors proportional to the reflected intensity and that voltage is given as an input to on-chip ADC of microcontroller [15]. The hardware specifications and the boundary conditions of the vehicle's hardware are given in table 1 . It includes the physical dimensions, mechanical restriction for the wheel to turn and boundary values of the PWM to be given to the servo motor for proper steering and the minimum turn radius that can be turned by the vehicle.

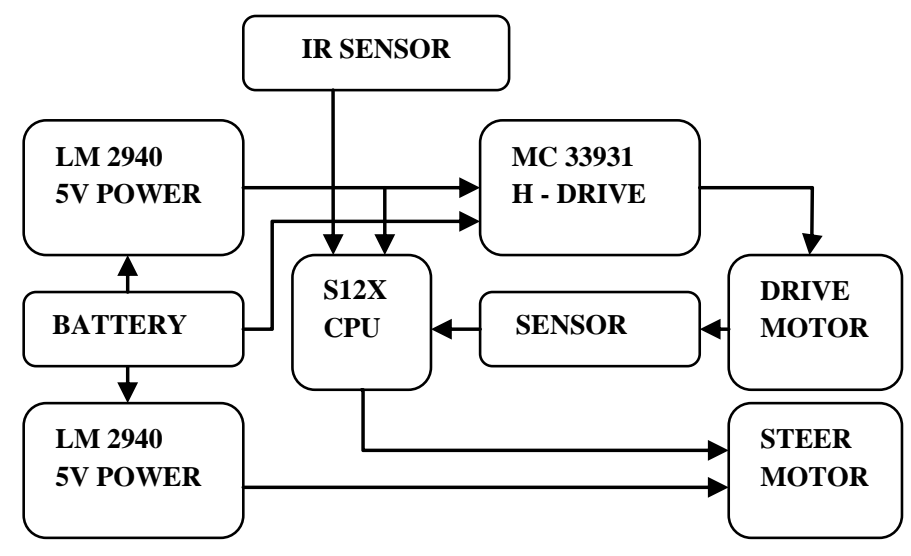

Figure 2: System Architecture

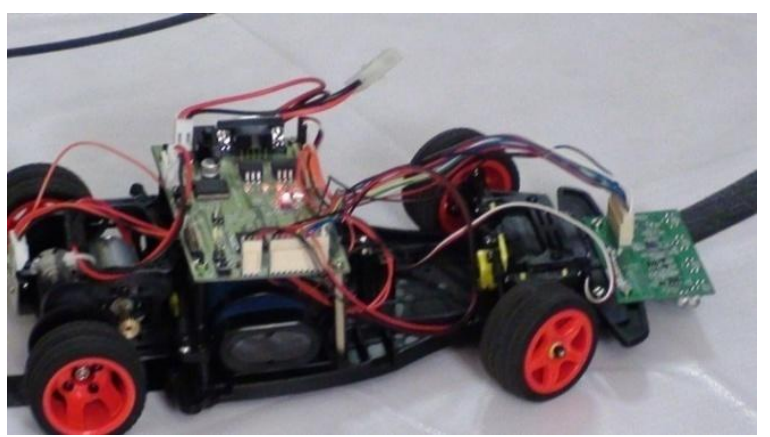

Figure 3: Self Guided Vehicle

Table 1. Hardware Specifications and Boundary Conditions

\begin{tabular}{|l|l|l|l|}
\hline Length & $32 \mathrm{~cm}$ & $\begin{array}{l}\text { Min. Right turn } \\
\text { radius }\end{array}$ & $50 \mathrm{~cm}$ \\
\hline Width & $16.5 \mathrm{~cm}$ & Min left turn radius & $54 \mathrm{~cm}$ \\
\hline Height & $8 \mathrm{~cm}$ & Centre duty cycle & $7 \%$ \\
\hline $\begin{array}{l}\text { Wheel } \\
\text { circumference }\end{array}$ & $17 \mathrm{~cm}$ & $\begin{array}{l}\text { Extreme left duty } \\
\text { cycle }\end{array}$ & $5.5 \%$ \\
\hline $\begin{array}{l}\text { Max. Right } \\
\text { turn angle }\end{array}$ & $40^{\circ}$ & $\begin{array}{l}\text { Extreme right duty } \\
\text { cycle }\end{array}$ & $8.5 \%$ \\
\hline $\begin{array}{l}\text { Max. Left } \\
\text { turn angle }\end{array}$ & $45^{\circ}$ & PWM duty per turn & $5.9^{\circ}$ \\
\hline
\end{tabular}




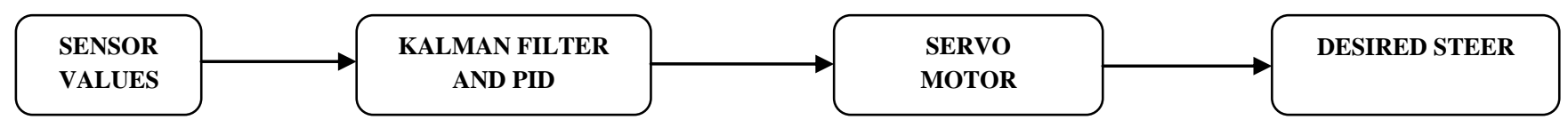

Figure 4: Open Loop control system in steer control

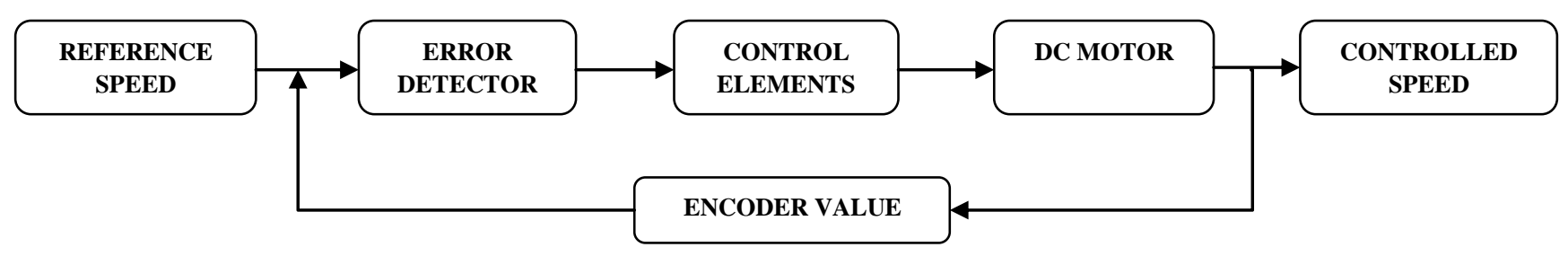

Figure 5: Closed loop control system in drive control

\subsection{Signal Conditioning and Control Methodology}

Analog signal from 7 phototransistors are connected to the seven on-chip analog channels of microcontroller which samples the sensor outputs and converts it into digital values. Error values are calculated based on the weights $(\mathrm{W})$ and position $(\mathrm{X})$ values of the sensors and is computed as follows.

$$
\begin{aligned}
& \text { Weights }(\mathrm{W})=(\mathrm{s} 1 \times 1)+(\mathrm{s} 2 \times 2)+(\mathrm{s} 3 \times 3)+(\mathrm{s} 4 \times 4)+ \\
& (\mathrm{s} 5 \times 5)+(\mathrm{s} 6 \times 6)+(\mathrm{s} 7 \times 7)-\cdots \\
& X=s 1+s 2+s 3+s 4+s 5+s 6+s 7 \\
& ----(2) \\
& E=W / X \\
& ----(3) \\
& \text { Error }=E-4
\end{aligned}
$$

The various possible sensor readings are analyzed and error values are calculated using equations (1) to (4) and the obtained error range are shown in table 2 .

Table 2. Estimated Error Value

\begin{tabular}{|c|c|c|c|c|c|c|c|c|c|c|}
\hline S1 & S2 & S3 & S4 & S5 & S6 & S7 & $\mathbf{X}$ & $\mathbf{W}$ & $\begin{array}{c}\mathbf{E}= \\
\mathbf{W} / \mathbf{X}\end{array}$ & $\begin{array}{c}\text { Error } \\
=\mathbf{E}-4\end{array}$ \\
\hline 1 & 0 & 0 & 0 & 0 & 0 & 0 & 1 & 1 & 1 & -3 \\
\hline 1 & 1 & 0 & 0 & 0 & 0 & 0 & 2 & 3 & 1.5 & -2.5 \\
\hline 0 & 1 & 0 & 0 & 0 & 0 & 0 & 1 & 2 & 2 & -2 \\
\hline 0 & 1 & 1 & 0 & 0 & 0 & 0 & 2 & 5 & 2.5 & -1.5 \\
\hline 0 & 0 & 1 & 0 & 0 & 0 & 0 & 1 & 3 & 3 & -1 \\
\hline 0 & 0 & 1 & 1 & 0 & 0 & 0 & 2 & 7 & 3.5 & -0.5 \\
\hline 0 & 0 & 0 & 1 & 0 & 0 & 0 & 1 & 4 & 4 & 0 \\
\hline 0 & 0 & 0 & 1 & 1 & 0 & 0 & 2 & 9 & 4.5 & 0.5 \\
\hline 0 & 0 & 0 & 0 & 1 & 0 & 0 & 1 & 5 & 5 & 1 \\
\hline 0 & 0 & 0 & 0 & 1 & 1 & 0 & 2 & 11 & 5.5 & 1.5 \\
\hline 0 & 0 & 0 & 0 & 0 & 1 & 0 & 1 & 6 & 6 & 2 \\
\hline 0 & 0 & 0 & 0 & 0 & 1 & 1 & 2 & 13 & 6.5 & 2.5 \\
\hline 0 & 0 & 0 & 0 & 0 & 0 & 1 & 1 & 7 & 7 & 3 \\
\hline
\end{tabular}

The proposed algorithm works satisfactorily for microcontroller operating with clock frequency as minimum as $0.5 \mathrm{MHz}$ which justifies that the proposed algorithm is code optimized. For having better resolution in steering, 16-bit PWM is used to control the servo mechanism [16]. 20ms PWM is used which updates the steer value of the motor once in $20 \mathrm{~ms}$ for smooth angular motion. The width of the pulse given is directly proportional to the angle of the servo motor. Servo motor control is an open loop control system as shown in figure 4. Using Kalman filter and PID the output is made to depend on the past sensor values and thereby indirectly giving it the needed feedback. DC motor is driven by Freescale MC33931VW H-bridge motor driver. To improve the reliability and better isolation, $\mathrm{H}$-bridge motor driver is used. Two PWM channels from the controller are connected to the H-bridge for forward and reverse motion control. Closed loop speed control is achieved with the help of encoder module as shown in figure 5.

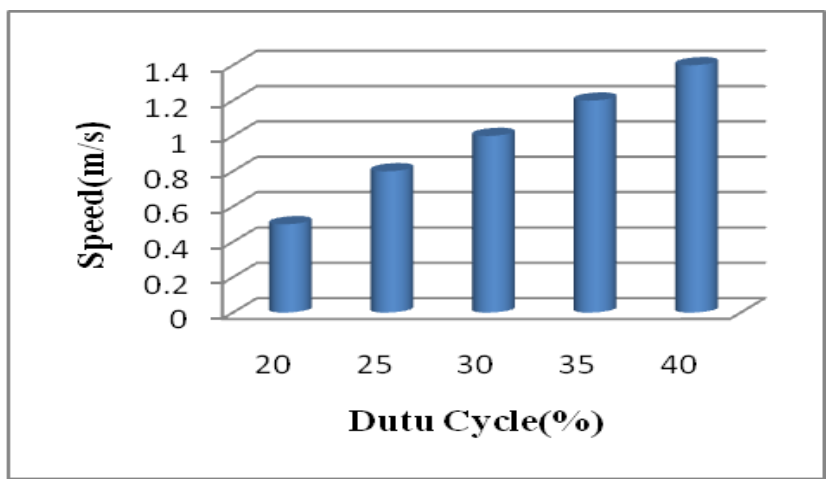

Figure 6: PWM Duty Value Vs Vehicle Speed

By altering the duty register value the speed of the vehicle can be varied. The speed of the vehicle with respect to the duty cycle is plotted and it can be seen that as the PWM duty cycle to DC motor is increased the speed of the vehicle increases correspondingly as shown in figure 6 .

\section{LATERAL CONTROL ORGANIZATION}

Two layer control architecture is proposed to manage the steer of the vehicle. The high level layer consists of Kalman filter which is used to act upon the acquired sensor inputs and to generate the necessary steer value [17]. The low level layer is composed of PID controller that receives the high level layer's command and controls the servo motor. This two level architecture has been organized on the basis of the cascade controlled architecture 
paradigm as depicted in figure 7. Kalman filter is an Adaptive filter. It is mainly used where the measurements observed over time contains noise and other inaccuracies. It computes weighted average of the predicted value and the measured value. Kalman filter works recursively and requires only the last "best guess" to calculate a new state. The equations of Kalman filter [18] are given as

$$
\begin{aligned}
& x_{t \mid t-1}=F_{t} x_{t-1 \mid t-1}+B_{t} u_{t} \\
& \mathrm{P}_{\mathrm{t} \mid \mathrm{t}-1}=\mathrm{F}_{\mathrm{t}} \mathrm{P}_{\mathrm{t}-1 \mid \mathrm{t}-1} \mathrm{~F}_{\mathrm{t}}^{T}+\mathrm{Q}_{\mathrm{t}} \\
& \mathrm{x}_{\mathrm{t} \mid \mathrm{t}}=\mathrm{x}_{\mathrm{t} \mid \mathrm{t}-1}+\mathrm{K}_{\mathrm{t}}\left(\mathrm{y}_{\mathrm{t}}-H_{t} x_{t \mid t-1}\right) \\
& \mathrm{K}_{\mathrm{t}}=\mathrm{P}_{\mathrm{t} \mid \mathrm{t}-1} \mathrm{H}_{\mathrm{t}}^{\mathrm{T}}\left(\mathrm{H}_{\mathrm{t}} P_{t \mid t-1} H_{t}^{T}+R_{t}\right)^{-1} \\
& \mathrm{P}_{\mathrm{t} \mid \mathrm{t}}=\left(1-\mathrm{K}_{\mathrm{t}} H_{t}\right) \mathrm{P}_{\mathrm{t} \mid \mathrm{t}-1}
\end{aligned}
$$$$
-\cdots-(5)
$$$$
-----(6)
$$

In a line tracking system, the car is expected to track the line without any deviations. Hence the next state of the system $\left(\mathrm{X}_{\mathrm{t}+1}\right)$ should be same as the present state $\left(\mathrm{X}_{\mathrm{t}}\right)$. Hence the system is modelled as

$$
\mathrm{x}_{\mathrm{t}+1}=\mathrm{x}_{\mathrm{t}}
$$

their familiarity in the field of control applications. The process of selecting the various coefficient values to make a PID controller perform correctly is called PID Tuning [19].

As depicted in the figure 8, for better steering control, the error readings is obtained from the IR sensors and are pre-processed for error calculation and error identification. The pre-processed error is then given to the high level control architecture (i.e.) Kalman filter. It eliminates the effect of noise and other disturbances in the input error values and provides with the necessary steer that has to be made for smooth response. The high level architecture's output is then fed to the low level architecture which has PID controller. Let Ei denote the present error and Ei-1 denote the error of previous iteration. If the absolute value of Ei is greater than the absolute value of Ei-1, the vehicle is deviating away from the track else the vehicle is retracing back to the track. PID controller enhances the steer as done by PI controller when the vehicle is deviating away from the track and diminishes the steer as in PD controller in-order to make a smooth retrace back to the track once the vehicle is aligned with the track. This filtered and control value is the correction that has to be accumulated with the centre PWM value in order to obtain the steer of desired angle. Hence the correction value added with the centre value is given as the PWM Duty value for the servo motor thus giving us the required steering action throughout the track with greater accuracy.

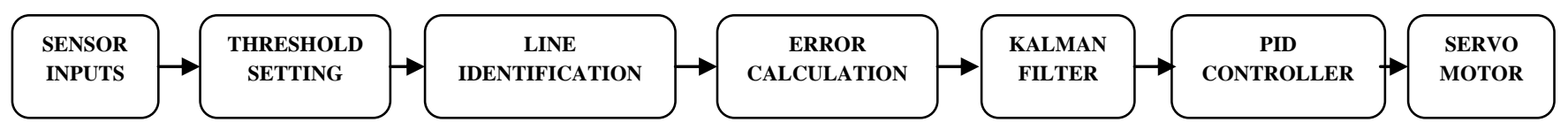

Figure 7: Lateral Control Flow

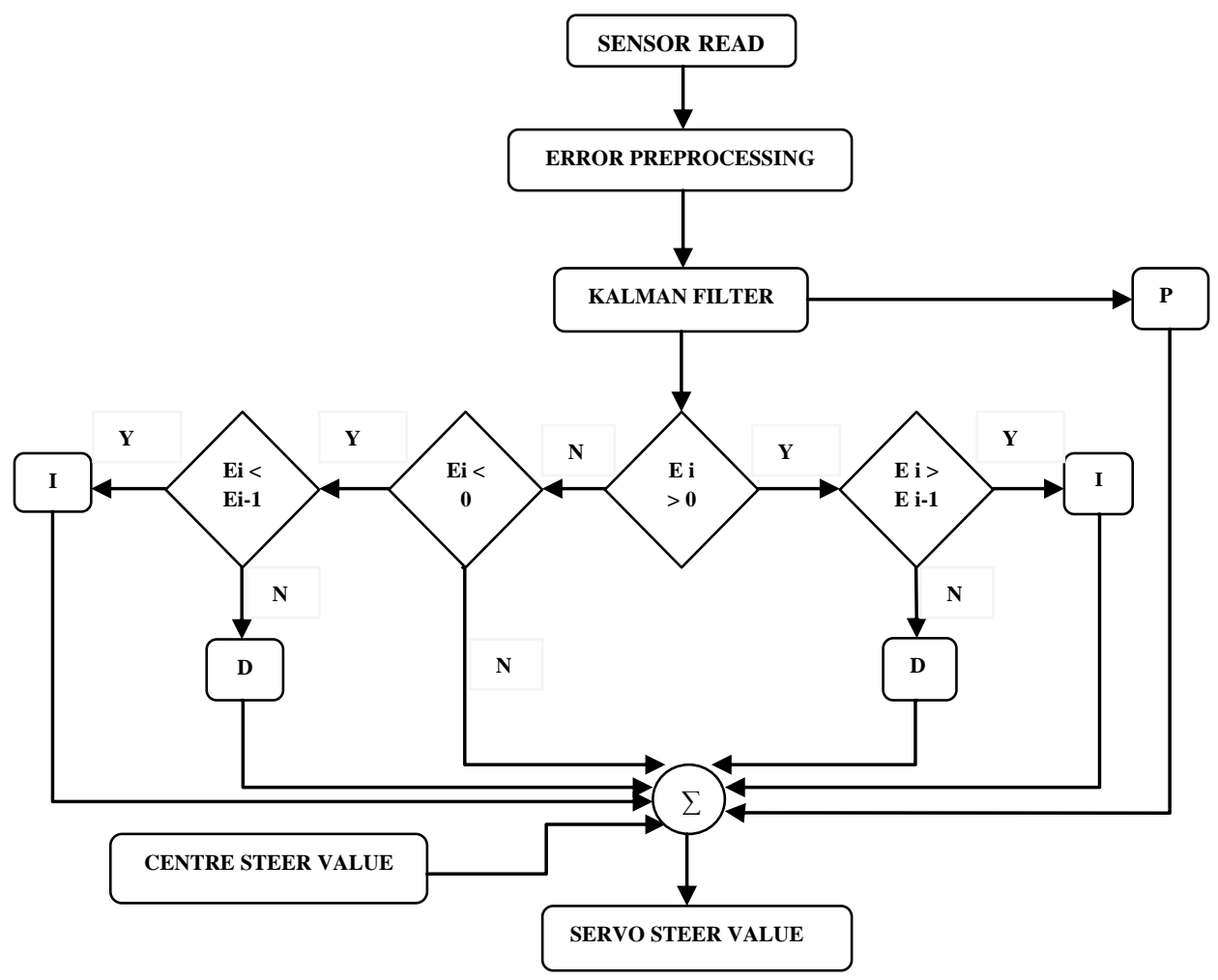

Figure 8: Lateral Control Algorithm 
The presence of Kalman filter also protects the steering action from external disturbances such as varying lighting conditions, sudden flashes and sensor misreading which if otherwise may cause instability to the vehicle and thereby making it to relinquish tracing the track. Thus the two level architecture of Kalman Filter and PID controller manages the lateral control of the autonomous self guided vehicle effectively.

\section{LONGITUDINAL CONTROL ORGANIZATION}

The longitudinal control of a vehicle includes various aspects regarding the speed of the vehicle. It covers adaptive speed control, adaptive cruise control, platooning and various other techniques. Due to various inescapable reasons the speed of the vehicle might get lowered than the expected value for a given input duty cycle of the dc motor. Some major instance that reduces the speed of the vehicle is the effect of changes in the power supplied by the battery and the friction produced between the wheels and the track as the vehicle takes a turn. This effect worsens if the vehicle takes a sharp turn. Presence of turns in the track is unavoidable and hence a suitable alternate algorithm has to be developed and employed to overcome this impediment. Thus adaptive speed control becomes mandatory in the automated self guided vehicle.

The flow chart in figure 9 clearly depicts the working of the proposed adaptive speed control algorithm. To maintain a constant speed, a feedback is obtained from the encoder and based on the difference between the encoder value which gives the true speed and from the desired or base speed of the car, necessary boosting is provided to maintain the speed.

Table 3. Speed Boosting Method

\begin{tabular}{|c|c|c|c|c|c|c|}
\hline $\begin{array}{l}\text { Boost } \backslash \text { PWM } \\
\text { Increment } \\
\text { for Iteration }\end{array}$ & 1 & 2 & 3 & 4 & 5 & 6 \\
\hline 0 & $\mathrm{BS}$ & $\mathrm{BS}$ & $\mathrm{BS}$ & BS & BS & $\mathrm{BS}$ \\
\hline 1 & $\begin{array}{l}\text { BS + } \\
1\end{array}$ & $\begin{array}{l}\mathrm{BS}+ \\
2\end{array}$ & $\begin{array}{l}\text { BS + } \\
3\end{array}$ & $\begin{array}{l}\text { BS + } \\
4\end{array}$ & $\begin{array}{l}\text { BS + } \\
5\end{array}$ & $\begin{array}{l}\text { BS + } \\
6\end{array}$ \\
\hline 2 & $\begin{array}{l}\text { BS + } \\
2\end{array}$ & $\begin{array}{l}\mathrm{BS}+ \\
4\end{array}$ & $\begin{array}{l}\text { BS + } \\
6\end{array}$ & $\begin{array}{l}\text { BS + } \\
8\end{array}$ & $\begin{array}{l}\text { BS + } \\
10\end{array}$ & $\begin{array}{l}\text { BS + } \\
12\end{array}$ \\
\hline 3 & $\begin{array}{l}\text { BS + } \\
3\end{array}$ & $\begin{array}{l}\text { BS + } \\
6\end{array}$ & $\begin{array}{l}\text { BS + } \\
9\end{array}$ & $\begin{array}{l}\text { BS + } \\
12\end{array}$ & $\begin{array}{l}\text { BS + } \\
15\end{array}$ & $\begin{array}{l}\text { BS + } \\
18\end{array}$ \\
\hline 4 & $\begin{array}{l}\text { BS + } \\
4\end{array}$ & $\begin{array}{l}\mathrm{BS}+ \\
8\end{array}$ & $\begin{array}{l}\text { BS + } \\
12\end{array}$ & $\begin{array}{l}\mathrm{BS}+ \\
16\end{array}$ & $\begin{array}{l}\text { BS + } \\
20\end{array}$ & $\begin{array}{l}\text { BS + } \\
24\end{array}$ \\
\hline 5 & $\begin{array}{l}\text { BS + } \\
5\end{array}$ & $\begin{array}{l}\mathrm{BS}+ \\
10\end{array}$ & $\begin{array}{l}\text { BS + } \\
15\end{array}$ & $\begin{array}{l}\text { BS + } \\
20\end{array}$ & $\begin{array}{l}\text { BS + } \\
25\end{array}$ & $\begin{array}{l}\text { BS + } \\
30\end{array}$ \\
\hline
\end{tabular}

The table 3 shows how the dc motor's PWM is varied in order to maintain the constant speed. In the table 'BS' denotes the Base speed and 'TS' the true speed of the vehicle. The 'Boost' is computed as the difference between the base speed and the true speed and depending upon the boost value the duty cycle is increased for every iterations in order to compensate the reduction in speed, which is depicted in figure 10.

Boost $=$ BS - TS

New Speed $=$ BS $+($ Boost $\times$ No. of Iterations $)--(12)$
Considering the vehicle is running with the base speed of 65 as PWM value or $32.5 \%$ duty cycle the adaptive speed control is plotted with PWM duty register value on ' $y$ ' axis and iterations on the ' $\mathrm{x}$ ' axis for different boost values as shown in figure 10 .

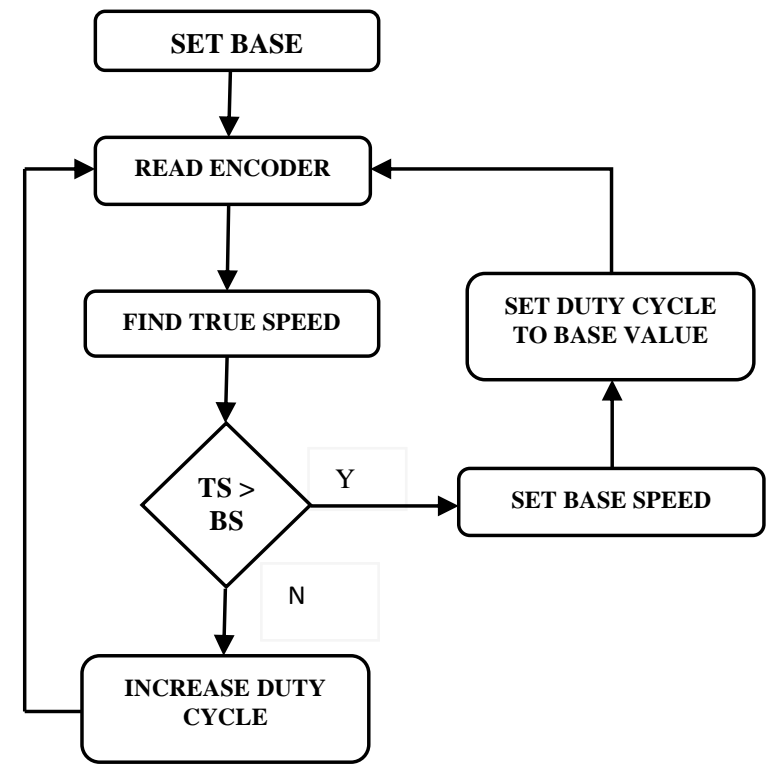

Figure 9: Adaptive Speed Control

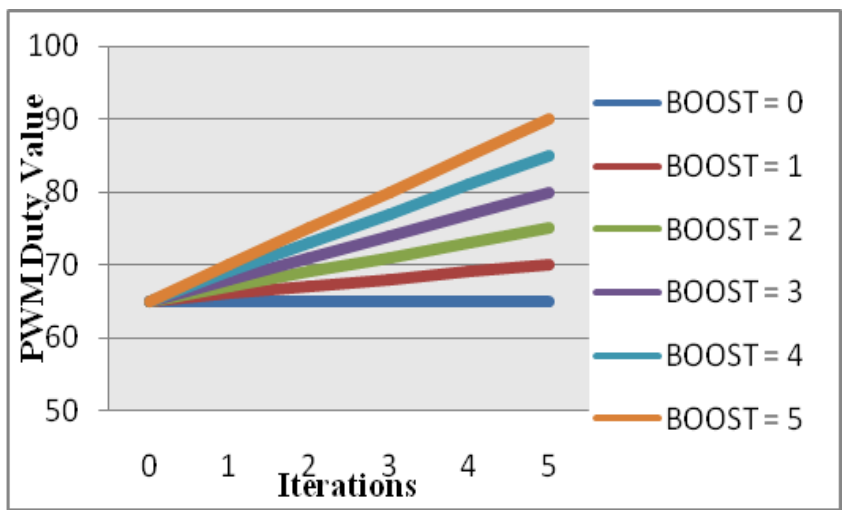

Figure 10: Iterations vs. PWM Duty Value (Adaptive Speed Control)

The proposed complete model of two layer lateral control architecture and adaptive speed control structure implemented in the vehicle is visualized in figure 11 .

\section{EXPERIMENTATION AND RESULTS}

Figure 12 shows a test bed track with $2.5 \mathrm{~cm}$ wide black line and with $1510 \mathrm{~cm}$ length which is used for testing the algorithms. The test bed track has three curves of three different radii $(60 \mathrm{cms}$, $66 \mathrm{cms}$ and $120 \mathrm{cms}$ ). The performance of the car in the straight line as well as in the three different curves is being observed and analyzed and the results are compared. The compared result shows that the proposed algorithm for lateral control and longitudinal control serves better than the other methods, which is clearly shown in the following sections. 


\subsection{Experimental Result Analysis}

Various tracking methods such as Kalman Filter, PID Controller and the proposed method are implemented and their results are compared. The lap completion time is plotted against the duty cycle and the obtained result is shown in figure 13.

Where * denotes the point from which the car becomes unstable. It is clear from the graph that PID and Kalman individually becomes unstable as the speed of the car is increased and the proposed model remains stable even at higher speeds. The tracking accuracy is plotted against the duty cycle which is shown in Figure 14. The tracking accuracy is made on a subjective analysis and the subjective criteria are given in the table 4 .

Table 4. Subjective Quality Criteria

\begin{tabular}{|c|c|c|}
\hline $\begin{array}{c}\text { Number of } \\
\text { deviations }\end{array}$ & $\begin{array}{c}\text { Subjective } \\
\text { Criteria }\end{array}$ & $\begin{array}{c}\text { Tracking } \\
\text { accuracy (\%) }\end{array}$ \\
\hline 0 & Excellent & 100 \\
\hline $1-3$ & Very good & 90 \\
\hline $3-5$ & Good & 80 \\
\hline $6-8$ & Fair & 70 \\
\hline $8-10$ & Poor & 60 \\
\hline More than 10 & Very poor & 50 \\
\hline Out of track & Worst & 0 \\
\hline
\end{tabular}

From the graph it can be seen that the tracking accuracy is better even at high speeds in the proposed model where the other methods lost their tracking accuracy and becomes unstable or leave the track.

Proposed model is compared with Gengyun's [20] and Ismail's [21] algorithm. The comparison chart in figure 15 shows the number of deviations made by the self guided vehicle under the same physical conditions such as track material and lighting conditions. Comparison chart shows that the proposed model has better tracking accuracy among the other tested algorithms.

While tracking, Overshoot or Undershoot made by the vehicle is observed for PID, Image processing method, Kalman Filter and the proposed method. The table 5 shows that, in the proposed method there is no overshoot/undershoot present.

Table 5. Comparison of various algorithms

\begin{tabular}{|c|c|c|c|c|}
\hline & PID & $\begin{array}{c}\text { Image } \\
\text { Processing }\end{array}$ & $\begin{array}{c}\text { Kalman } \\
\text { Filter }\end{array}$ & $\begin{array}{c}\text { Proposed } \\
\text { Method }\end{array}$ \\
\hline Overshoot & Present & $\begin{array}{c}\text { Minimally } \\
\text { present }\end{array}$ & Absent & Absent \\
\hline Undershoot & Present & $\begin{array}{c}\text { Minimally } \\
\text { present }\end{array}$ & Absent & Absent \\
\hline
\end{tabular}

Also from the experimental results it has been seen that the proposed method is more stable than other algorithms and it works well even at high speeds where all the other algorithms failed. A comparison is also made between the previously existing Kalman Filter model and the proposed model. In Kalman filter based design, the parameter $\mathrm{P}$ plays a vital role as it gives the error in the estimation of the state [22]. The value of $\mathrm{P}$ should be maintained as low as possible towards 0 . Lower the $\mathrm{P}$ value towards 0 , more accurate the estimated state of the system is. Thus a comparison is made among the $\mathrm{P}$ values of the Oscar's Method [23] and the proposed model and the result is shown in Table 6.

Table 6. Comparison of $P$ value

\begin{tabular}{|c|c|}
\hline OSCAR'S Method & Proposed Method \\
\hline $\mathrm{P}=0.07$ & $\mathrm{P}=0.0031$ \\
\hline
\end{tabular}

Thus from table 6 it is evident that the estimated state of the proposed model is more reliable than that of the Oscar's Method. Thus by the comparisons made between the proposed model and various other existing methods, the proposed method proves to be better when compared in terms of reliability, accuracy and in speed. The existing techniques lose their accuracy in case of improper or changing light conditions which is common in real time environment. Since the proposed model has scalar relationships there is no vector calculations involved so implementation in any software is easy and thus code complexity is minimized.

\section{CONCLUSION AND FUTURE SCOPE}

Thus from the proposed model, it can be seen that by using Kalman filter and PID in line tracking, the errors in existing models had been overcome. When implemented in S12X microcontroller based self guided vehicle, proposed algorithm gave desired results thus validating its efficient performance. From the comparison results the deviations and tracking efficiency of proposed model has given desired results and it remains stable even at higher speeds. Hence the proposed model will be a good substitute for the commonly used existing techniques. This work can further be extended to incorporate various other ITS techniques such as vehicle platooning, adaptive cruise control and vehicular area networking (VANET).

\section{ACKNOWLEDGMENTS}

The authors like to thank Freescale Semiconductors for providing us the hardware and software to work on it. The authors like to thank Management and Principal, PSG College of Technology for supporting us to complete the work. 


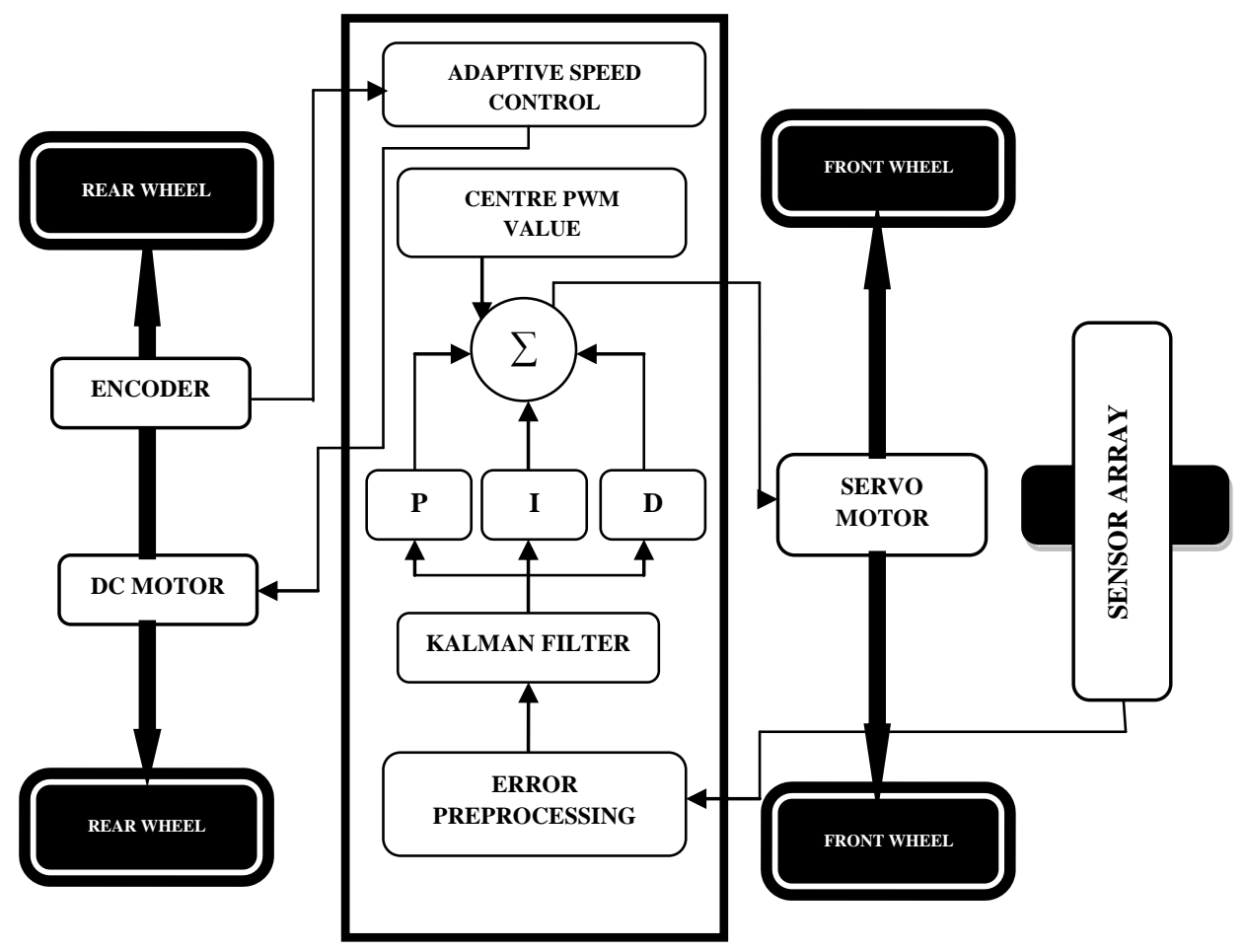

Figure 11: Complete model of Autonomous Self Guided Vehicle

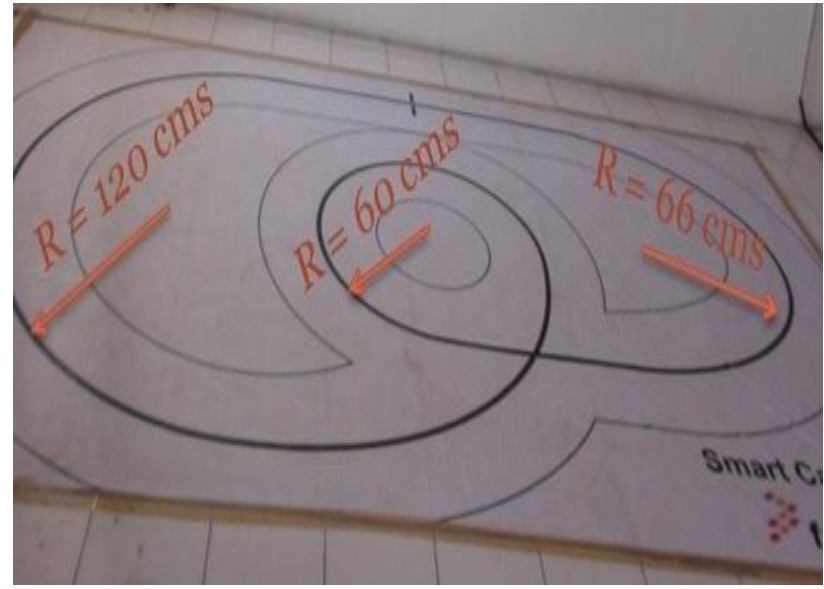

Figure 12: Test Bed Track

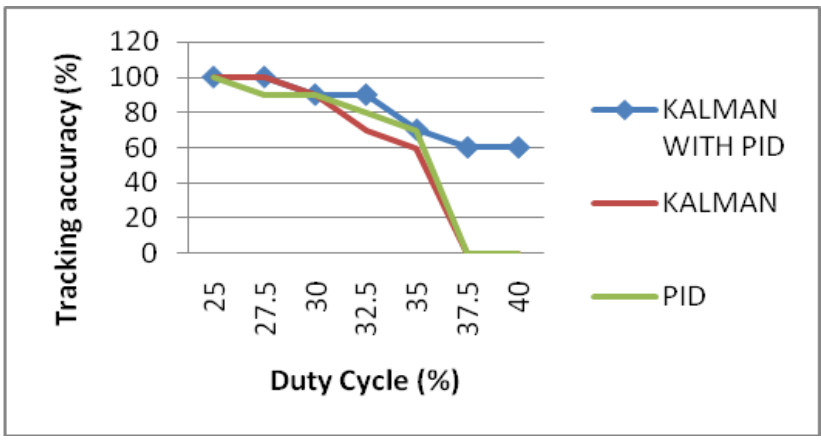

Figure 14: Comparison of various algorithms

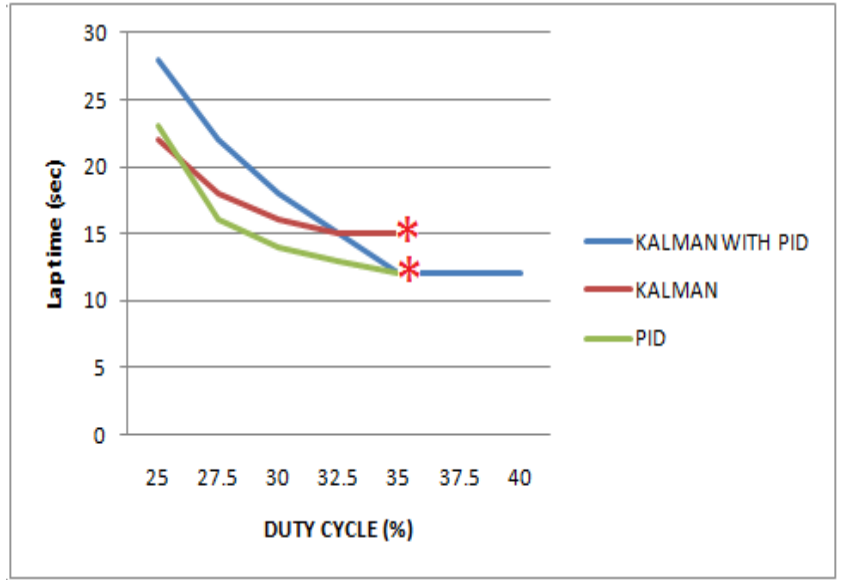

Figure 13: Comparison Chart (Duty Cycle vs. Lap Time)

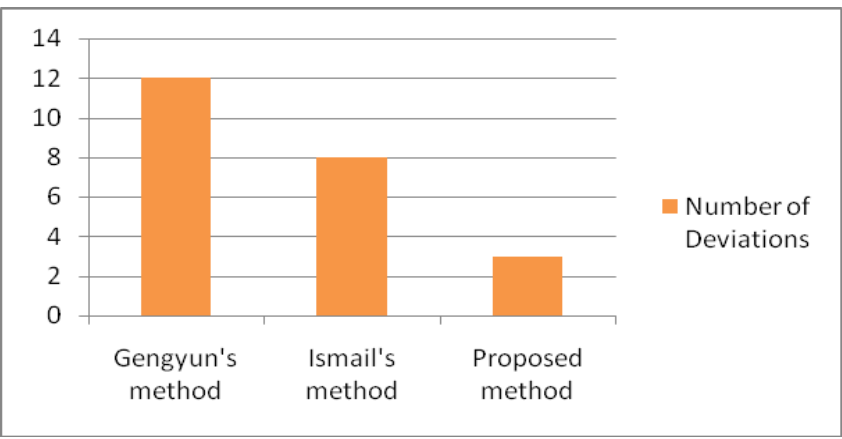

Figure 15: Comparison of different methods 


\section{REFERENCES}

[1] Andrisano O., Verdone R., Nakagawa M. 2000 'Intelligent Transportation Systems: The Role of Third Generation Mobile Radio Networks', IEEE Communication Magazine, 38, (9), pp. 144-151.

[2] Toral S., Vargas M., Barrero F. 2009 'Embedded Multimedia Processors for Road-Traffic Parameter Estimation', Computer, 42, (12), pp. 61-68.

[3] European Transport Policy for 2010: Time to Decide, White Paper, Luxembourg: Office for Official Publications of the European Communities, 2001. L-2985.

[4] Presentation on Intelligent Transportation System by Beverly Kuhn.

[5] Centennial Engineering, inc., 1992 'Survey on Intelligent Vehicle High-way System, Denver metro Area', for the Coloroda Department of Transportation, (October 1992).

[6] S.L. Toral M.R, Martı'nez Torres, F.J. Barrero M.R, Arahal , 2010 'Current paradigms in Intelligent Transportation Systems’, IET Intelligent Transport Systems, 12th May 2010.

[7] Alberto Martin, Hector Marini and Sabri Tosunoglu, 'Intelligent Vehicle / Highway System: A Survey', Florida International University, Department of Mechanical Engineering.

[8] Automated Vehicle Guidance (AVCS) - The Real Automobile at: http://www.azinet.com/articles/real98.htm

[9] M. El koursi, Ching-Yao Chan and Wei-Bin Zhang, 'Preliminary Hazard Analyses', 2008 IEEE symposium on Intelligent Vehicles, (4th June 2008).

[10] 'A Case study of Advanced Vehicle Control and Safety Systems', Systems, Man, and Cybernetics, 1999. IEEE SMC '99 Conference Proceedings, Tokyo, Japan, (12 October 1999).

[11] Steven E. Shladover, 1993 'Research and Development Needs for Advanced Vehicle Control Systems', Micro IEEE, volume 13, issue 1, (February 1993).

[12] S. Kato, S. Tsugawa, K. Tokuda, T.Matsui, and H. Fujiri, 2002 'Vehicle control algorithms for cooperative driving with automated vehicles and inter-vehicle communications', IEEE Transactions on Intelligent Transportation System, vol. 3, no. 3,pp. 155-161, (September 2002).
[13] Jóse E. Naranjo, Carlos González, Ricardo García, Teresa de Pedro, and Rodolfo E. Haber, 2005 'Power-Steering Control Architecture for Automatic Driving', IEEE transactions on intelligent transportation systems, vol. 6, no. 4, (December 2005).

[14] D. Pomerleau, 1995 'RALPH: Rapidly adapting lateral position handler', in Proceedings of IEEE Intelligent Vehicles Symposium, Detroit, MI, pp. 506-511.

[15] Adarsha Rao, Pramod Udupa, Alexander Fell, 2010 'Report on Design and Implementation of Line Following Car with Freescale S12X Microcontroller', Indian Institute of Science, (September 23, 2010).

[16] David Wilson, '16-Bit DSP Servo Control with the MC68HC16Z1', datasheet from Freescale Semiconductor, Inc.

[17] B.S. Rao, H.F. Durrant-Whyte, 1991 'Fully Decentralised algorithm for Multisensory Kalman filtering', Paper 7901D (C8), IEEE proceedings-d, vol. 138, no.5, (September 1991).

[18] http://www.cs.auckland.ac.nz/TeachAuckland.html/mm/MI6 3slides.pdf

[19] Julio E.Normey-Rico, Ismael Alcal!a, Juan Glomez-Ortega, Eduardo F. Camacho, 2001 'Mobile robot path tracking using a robust PID controller', Control Engineering Practice journal, (September 2001).

[20] Gengyun Yao, Fengxiang Gao, Changsong Wang, Xiao Chen, 2009 'Design and Simulation Based on Kalman Filter Fuzzy Adaptive PID Control for Mold Liquid Level Control System', Control and Decision Conference, 2009. CCDC '09. Chinese, Guilin, (17-19 June 2009).

[21] A.H. Ismail, H. R. Ramli, M. H. Ahmad, and M. H. Marhaban, 2009 'Vision-based System for Line Following Mobile Robot', 2009 IEEE Symposium on Industrial Electronics and Applications (ISIEA 2009), Kuala Lumpur, Malaysia, (October 4-6, 2009).

[22] Leonie Freeston, 'Applications of the Kalman Filter Algorithm to Robot Localisation and World Modelling', Electrical Engineering Final Year Project 2002 University of Newcastle, NSW, Australia.

[23] Oscar Laureano Casanova, Fragaria Alfissima, Franz Yupanqui Machaca, 2008 'Robot Position Tracking Using Kalman Filter', Proceedings of the World Congress on Engineering, Vol. II, London, U.K, (July 2 - 4, 2008). 